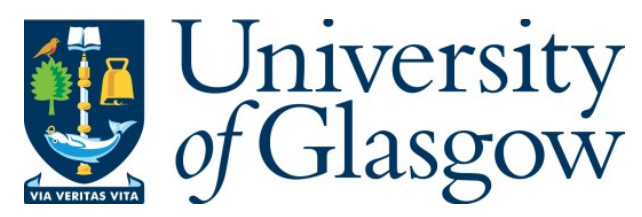

Brooks, O., and Burman, M. (2016) Reporting rape: victim perspectives on advocacy support in the criminal justice process. Criminology and Criminal Justice, (doi:10.1177/1748895816667996).

There may be differences between this version and the published version. You are advised to consult the publisher's version if you wish to cite from it.

http://eprints.gla.ac.uk/122862/

Deposited on: 16 August 2016

Enlighten - Research publications by members of the University of Glasgow http://eprints.gla.ac.uk 


\title{
Reporting rape: victim perspectives on advocacy support in the criminal justice process
}

\section{Oona Brooks and Michele Burman, University of Glasgow, UK}

\begin{abstract}
Concerns about the criminal justice response to rape have prompted the development of victim $^{1}$ advocacy services across a range of jurisdictions, yet research evidence about the nature, meaning and value of advocacy remains limited. This paper draws upon a study evaluating an innovative advocacy model introduced in Scotland to assist reporting rape to the police. Findings from interviews with nine victims highlight the importance of advocacy that is independent of statutory and criminal justice agencies. However, it is argued that this does not mitigate the need for specialisation or reform in the criminal justice response to rape and, further, that the distinction between advocacy at an individual and societal level represents a false dichotomy.
\end{abstract}

\section{Key words:}

Rape, sexual assault, sexual violence, advocacy, police, victim

\section{Introduction}

The failure of conventional criminal justice systems to address the needs of those who have experienced sexual violence is well documented (McGlynn et al., 2016) and there are several longstanding concerns about the criminal justice response to rape in particular. Key amongst these are the 'secondary victimisation' experienced by victims arising as a result of the

\footnotetext{
${ }^{1}$ The term 'victim' is used through out this paper, reflecting the criminal justice context of the discussion. However, the term 'survivor' is often preferred as a more empowering term when discussing sexual violence.
} 
investigative, prosecution and court room processes, which can exacerbate the trauma of the rape (Brown et. al., 1993; Burman, 2009; Kelly et al., 2005; Maier, 2008); high levels of case attrition (Brown, 2011; Daly and Bouhours, 2010; Lovett and Kelly, 2009); and low or declining levels of conviction (Hohl and Stanko, 2015; Kelly et al., 2005). Since the 1970s, problematic police attitudes which privilege a 'real rape' construct (Estrich, 1987) over other rape contexts, and which cast doubt on the veracity or credibility of the victim's account, have been subjected to intense feminist critique (Gregory and Lees, 1999; Jordan, 2001). Research internationally has found the 'attrition problem' (Brown, 2011) to be particularly high at this early reporting stage due to a variety of reasons: the suspect cannot be located or identified; the police believe there is insufficient evidence; or the victim decides to withdraw the complaint (Daly and Bouhours, 2010; Harris and Grace, 1999; Lea et al., 2003; Lovett and Kelly, 2009). The statement provided to the police by the victim is crucially important at this point; as part of this victims may be asked to recount the minutiae of the rape, their dress, lifestyles and their behaviour towards the suspect (Jordan, 2001; 2011; McMillan and Thomas, 2009). Unsurprisingly, many victims find these early encounters traumatic and are reluctant to engage with the criminal justice system or seek further help (Campbell and Raja, 1999; 2005; Campbell, 2006).

In response to criticism, police in many jurisdictions have introduced improvements to their response to rape, including specialist policing roles and teams (McMillan, 2014; Westmarland et al., 2012). Additionally, concerns about responses to violence against women more generally have provided the impetus for developing advocacy services to assist victims in their interactions with criminal justice, health and other agencies. Kelly (2005) has described the use of advocates as promising practice. However, there are differing definitions, understandings and purposes of advocacy, each with distinctive characteristics relating to the nature of work undertaken and the organisations that advocacy services are located within. Existing research evidence, and the case for advocates, is based primarily on 
the success of advocacy in domestic violence cases (Howarth et al., 2009; Parmar et al., 2005; Sullivan, 1991; Taylor-Dunn, 2016; Vallely et al., 2005) and, with few exceptions (e.g. Campbell, 2006; Robinson, 2009), there is limited research evidence about the value and efficacy of advocacy support in relation to rape (Daly, 2011; Rich, 2014). Moreover, there is a lack of research from the perspective of victims exploring the implications of advocacy, differences in its provision, and specifically, whether it is important for advocacy services provided to victims of sexual violence to be independent of police and other statutory partners (Robinson and Hudson, 2011).

This article examines these questions from the under-researched perspective of rape victims. It draws on empirical material from an evaluation of the pilot phase of a rape advocacy service, 'Support to Report' (S2R), which was introduced in Scotland to 'assist male and female victims at the initial stage of making a report to the police' (Brooks et al., 2015). Rather than simply addressing the question of whether advocacy work is of any intrinsic value to rape victims, this paper examines why and in what context, and by so doing considers the wider implications of advocacy for the criminal justice response to rape.

The article is in three sections: the first considers the differing meanings of advocacy in the context of criminal justice responses to violence against women; the second reviews developments in the provision of specialist responses to rape as a means of contextualising the increased range and use of advocacy services; and the third draws on qualitative interview data with S2R users to highlight their perceptions of the advocacy and criminal justice process. We argue that rape advocacy is particularly important for enabling informed choices by victims and for ameliorating 'secondary victimisation' at the reporting stage and beyond. In this context we understand 'secondary victimisation' to mean the additional trauma experienced by rape victims due to victim blaming or otherwise insensitive responses within the criminal justice system (Jordan, 2001; Skinner and Taylor, 2009). We 
conclude with a discussion of the benefits of rape advocacy independent of criminal justice agencies for engagement with victims, which is consistent with research on advocacy in other criminal justice contexts (Hucklesby and Worrall 2007; Robinson 2009; Taylor-Dunn 2016), and for meeting victims' conceptions of justice (McGlynn et al., 2016). Finally, we highlight the implications of this analysis for future research and practice.

\section{Understanding advocacy}

Drawing upon data from several jurisdictions (including Australia, New Zealand, Canada, South Africa, the UK and the US), Daly (2011) provides a four-part inventory of conventional and innovative responses to sexual violence comprising of: specialisation; offender focus; legal reform; and victim advocacy and participation. Of particular relevance here is the provision of specialised services and victim advocacy. Advocacy services exist worldwide, although their nature and provision is varied and they are relatively scarce in less affluent states (Rich, 2014). Within the EU, specialist advocates for victims of sexual violence are known to exist in 14 countries, including the UK, Austria, Denmark, France, Germany and Ireland (Walby et al., 2015). Meanwhile, Victim Advocate Officers and Victim Advocates exist in South Africa and the US respectively (Campbell, 2006; Sadan et al., 2001). In the context of criminal justice and other agency responses to victims of violence against women, however, the term 'advocacy' has varied meanings across differing jurisdictions and settings and there is a relative lack of research evidence about their operation.

According to Kelly and Humphreys (2000) it is the emphasis on rights and entitlements which distinguishes advocacy from other forms of support. The term 'victim advocacy' is used, particularly in the US, to denote services provided by organisations that emerged from the women's movement such as Women's Aid and Rape Crisis (Campbell, 2006) where feminist advocates developed principles and practices based on ideologies of collaboration and empowerment. Conceptions of advocacy situated at the level of individual support 
describe the role of victim advocates as providing information and advice, making referrals, explaining options, and accompanying victims to police stations or medical examinations, and/or providing support during court and post-court processes (Parkinson, 2010). By contrast, some organisations define advocacy primarily in terms of political activism; the feminist network Women Against Violence Europe (WAVE), for example, describe the advocacy work that they do as, 'Influencing policy makers to promote, protect and strengthen the human rights of women and children in Europe' (Blank et al., 2014: 4).

Further distinctions can be drawn according to the organisations within which advocates are located. The terms 'community-based advocacy' and 'system-based' advocacy are used to differentiate between independent advocates and those employed by statutory law enforcement agencies or who work in close collaboration with them as part of a multi-agency approach (Coy and Kelly, 2010; Rich, 2014; Robinson, 2009). Victim advocacy providers have evolved to include more organisations, notably health, social service and criminal justice agencies, with whom they work collaboratively; a development which has attracted criticism on the basis that this represents an erosion of independence and feminist ideals (Nichols, 2014). Careful consideration of how rape advocacy is defined and understood is therefore required, both in terms of the implications for policy and practice in different contexts, and also for how services may be experienced by victims.

\section{Developments in specialist support for victims of rape in the UK}

In the UK, all jurisdictions have recognised the need to increase access to support and health services for rape victims (see: Home Office 2007, 2011; Scottish Government, 2009); key provisions, discussed below, include dedicated support services such as Rape Crisis Centres and Sexual Assault Referral Centres (SARCs) and the development of specialist support and advocacy roles, including Independent Sexual Violence Advisors (ISVAs) in England and Wales. RCCs and SARCs both provide specialist support, but operate different models of 
service provision and have different origins. Whilst RCCs have grown out of the women's movement, SARCs are government-led multi-agency initiatives and are far more prominent in England and Wales; currently only one SARC exists in Scotland (Archway in Glasgow, introduced in 2007).

Since the 1970s, RCCs have operated as independent voluntary sector organisations offering services, primarily to women who have experienced rape or sexual assault. They may work with police to provide support to those going through the criminal justice system, however, they also have an autonomous role in providing support for victims who choose not to report to the police (Daly, 2011; Westmarland et al., 2012). Crucially, they have been at the forefront of raising awareness of sexual violence and influencing the public and statutory response to victims (Brindley and Burman, 2012; Jones and Cook, 2008). This work is underpinned by a feminist analysis of sexual violence and the associated belief that violence against women is a consequence of structural inequality (Nichols, 2013). SARCs, on the other hand, tend to involve a partnership approach between police and health services, offering a 'one-stop shop' providing both immediate and long-term support for victims (Robinson et al., 2008); indeed the provision of 'an interface between two large, bureaucratic systems: health and criminal justice' is seen as an important feature (Robinson and Hudson 2011: 523).

In the UK, between $2011 / 12$ to $2014 / 15$, the Government provided $£ 1.72 \mathrm{~m}$ p.a. to part fund 87 ISVA posts in England and Wales, to be located within both SARCs and in Rape Crisis to provide a point of contact and co-ordination of services for victims. While ISVAs don't currently exist in this form in Scotland, their role is akin to that of the 'advocacy worker' within the S2R advocacy service which forms the basis of the current study. The support provided by an ISVA is determined by the individual needs of the victim, however key elements of this support include advice on availability of counselling and other services, and information on the criminal justice process (UK Government, 2015). Following an 
examination of specialist support, including that provided by ISVAs, within the setting of SARCs compared to voluntary sector organisations in England and Wales, Robinson and Hudson (2011) conclude that while there were distinct challenges and benefits associated with service provision in both settings, they should be viewed as complementary approaches. Service providers in their study expressed support for SARCs on the one hand, but felt that independence from statutory partners was required for the delivery of effective services for victims.

In summary, within the UK, the range of specialised and dedicated services available has expanded to include specialist policing roles, ISVAs, dedicated support organisations such as RCCs and SARCs. It is within the context of these developments, and an appreciation of the limitations of the criminal justice response to rape, that the Support to Report (S2R) pilot advocacy service was launched in Scotland.

\section{Support to Report (S2R)}

S2R was launched as a new model of 24-hour advocacy support in December 2013 to assist rape victims at the initial stage of reporting to police. Its objectives were to improve the support available to victims of rape, to improve their experience of the criminal justice process, and reduce levels of rape attrition. Unlike some advocacy services, where advocacy workers are based within a referral centre, S2R is based in Glasgow Rape Crisis Centre and was initially designed to be offered by the police to those reporting rape with an on-call advocacy worker called out to attend within an hour. However, in response to victim needs, the service quickly evolved to encompass support delivered before, during and after reporting to police (up to and including at trial). The S2R pilot received joint funding from the Scottish Government via Rape Crisis Scotland and Police Scotland, though its delivery by Rape Crisis trained workers informs the non-judgemental, empowering, survivor-led approach to service delivery. 
The evaluation of S2R was conducted over a 12-month period from February 2014. Findings presented here draw qualitative semi-structured interviews were conducted with nine adult female rape victims who used the service; though this represents a small sample, valuable insights were gleaned from a particularly sensitive and difficult to reach population. This process was facilitated by adopting a qualitative research strategy to 'access the world in terms of those people being researched' (Stroh, 2000: 197). Interviews were used to ascertain victims' experiences of receiving advocacy support, and the impact this had on their experience and engagement with the criminal justice process. Recruiting victims for interview was particularly important, but also challenging due to the sensitive nature and timing of the advocacy support offered; S2R staff provided invaluable assistance in informing service users about the evaluation at a point deemed appropriate by the relevant advocacy worker. Victims who consented to have their contact details passed on to the evaluation team were then invited to participate in interview. It is acknowledged that there could have been reluctance on the part of advocacy workers to pass on the contact details of any individual deemed likely to give negative feedback about the project, however, the sensitive nature and timing of the research precluded other recruitment strategies.

Of the nine interviews, six related to recent incidents and three to historical incidents. In four cases the perpetrator was a partner/ex-partner and, in five cases, known to the victim. The small sample size precludes any meaningful analysis of how views may vary according to age, gender, disability or sexual orientation; however, it is acknowledged these factors are known to impact upon the specific needs of victims (Rich, 2014). All interviews were fully transcribed and analysed thematically. During analysis a Framework matrix-based approach (Ritchie et al., 2003) was adopted, thus allowing data to be synthesised and charted in a way that enabled the researchers to 'read across' data without losing sight of individual 
participants. Using this method was particularly important for highlighting connections both within and across participants' accounts. 


\section{Findings}

Key themes that emerged in relation to victims' views and experiences of accessing advocacy support were: victim participation and ability to make informed choices about engagement in the criminal justice process; independence of advocacy support to address needs throughout and beyond the criminal justice process; and provision of practical and emotional support in coping with the criminal justice process and the reactions of others. These themes are discussed in detail below, using anonymised verbatim extracts from interviews for illustrative purposes.

\section{Victim participation and ability to engage}

All interviewees, irrespective of the point within the reporting process that they accessed the service, described advocacy support as impacting positively on their ability to engage in, and continue with, the criminal justice process.

VS06: It amazes me that it's only a wee trial [pilot project] because I think, god, see if it hadn't been for Support to Report and [Advocacy Worker]... I don't know if I could have done it [reported to the police]... it makes such a difference.

Interviewees said that the non-judgmental support they experienced was key in enabling them to make a report, and that the provision of information, advice and support during and after the police statement influenced their ability to continue.

VS02: I think if that [S2R] wasn't there, I probably wouldn't have continued. Because I wouldn't have been able to, like I wouldn't have been able to phone the police up and chase things up. And I would have just left it.

As well as impacting on the level of engagement, in some cases, the provision of advocacy support contributed to the clarity of information provided by victims to the police. The 
specialist expertise of the advocacy workers, particularly in terms of their knowledge and understanding of the victim experience, was a key contributor in this regard.

VS09: ... if they [police] were asking me a question and I was maybe not getting it or being a bit hysterical... [Advocacy Worker] was like explaining for me, to them, like because she was getting what I was saying... Because they were saying that what I was saying didn't make sense, because they thought I was drunk and I didn't remember these people's names, but I actually don't know them... I wasn't explaining that clearly because I was so hysterical.

In addition, to understanding the victim experience and drawing links between different incidents, advocacy worker's knowledge of the criminal justice process was of particular value in providing reassurance.

VS06: ...at the time, I really needed somebody there. It, kind of, puts you at ease a wee bit as well because it's quite, the police were great, but it's quite scary sitting giving statements to the police. If there's somebody else there that understands it... It's definitely good.

In line with the findings of research on advocacy provided in other criminal justice contexts, the independence of advocacy workers enables engagement in a way that statutory services have long found difficult (Huckelesby and Worrall, 2007; Robinson, 2009; Taylor-Dunn, 2016). Advocacy support received at an early stage in the criminal justice process bolstered victims confidence, and helped them make informed choices which influenced their decision to continue beyond the initial police statement. It was also suggested that being able to give a statement to the police in RCC premises alleviated some of the difficulties associated with this process. In contrast to the more functional environment of a police station, RCC premises provided a more comfortable and child-friendly environment for giving a police statement and recalling the details of the rape. 


\section{Independent advocacy support throughout the criminal justice process}

Advocacy workers were also seen as taking on a valuable co-ordinating role, particularly in liaising with, and across, the police and other agencies following the initial statement. The weeks and months following an initial report is a time where contact with police becomes less frequent (although investigation activities may be ongoing) and while victims are invited to contact the police if they have any queries following their initial report, they articulated difficulties in doing so.

VS02: At that point, I hated the police officers questioning me... the thought of seeing them again and having to speak to them again, 'cause they scared me a bit. I don't know why, like it's ludicrous, 'cause they didn't do anything to me. But, so it was good, 'cause [Advocacy Worker] kind of worked as a go-between. And usually you want to kind of get rid of the middle men, but in this situation it was quite good.

Having an independent advocacy worker to follow-up information with the police was described as especially valuable given that victims may, understandably, feel nervous about making contact with the police due to the personal nature of their case and the formal role of the police within the investigation process. For others, it took some of the stress out of the process. Moreover, having an advocacy worker, with a dedicated role supporting victims was deemed to be particularly important due to the perception that police have other priorities associated with their investigative role.

VS02: The fact that they [police] say, oh we'll get back to you about this, and then they don't get back to you. And you're sitting... I get that they're busy and stuff... But I just think sometimes the victims are forgotten about, 'cause it's not a priority to the police. The priority to the police is getting criminals... I don't know if something needs to change with that, but I don't know how they'd do that. I just felt, I had a horrible, horrible experience [crying]. 
In addition to enhancing communication with the victim, the independent status of the advocacy worker also allowed for police practice to be challenged where appropriate. Advocacy support in navigating the criminal justice system following a report to police was highly valuable to victims due to their lack of familiarity with the system, coupled with limitations in their ability to cope with this aspect of their experience while processing and recovering from the rape itself.

VS06: ...as it went on there was things like I was able to ask her... like she spoke to the Procurator Fiscal'2, she helped me fill out my compensation forms, and all of that. She was brilliant. See just things that my head couldn't deal with at the time... because, I mean, I wouldn't even have thought of phoning the Procurator Fiscal... but when I spoke to [Advocacy Worker] it was great... I didn't even know what police station he'd been in but she was able to find it all out and it was, it was really good.

The provision of a consistent point of contact, was considered beneficial in view of the lengthy nature of the criminal justice process and the number of different agencies and individuals that may be involved in processing individual cases.

VS04: It makes it a lot simpler... you don't need to explain, because every time you meet a new person, you need to explain the circumstances, you need to explain what happened, what you went through, how you felt, how you're feeling now, explaining to them about stupid things like the threats, the feelings, stuff like that, whereas if it's the same person, they go through it with you, they know exactly what's going on, they know what's going to happen next.

The possibility that they may need to appear in court was particularly challenging for victims; indeed the prospect of going to court emerged as a greater concern than reporting to the police per se. Support in preparing for this eventuality, and in liaising with the Procurator

\footnotetext{
${ }^{2}$ In Scotland 'Procurator Fiscal' is the term used for the public prosecutor.
} 
Fiscal, was again valued due to the sense some interviewees had of the intimidating and distressing nature of these formal processes. Although the service was established with the aim of improving experiences of the criminal justice system and reducing the level of attrition, it was also apparent that there is an acute need for support in cases which do not progress (e.g. due to insufficient evidence) because of the particularly distressing nature of this outcome.

VSO3: ...it's been a bit of a kind of hard time, and I think that's probably where the police really need to have a big think about it. That if this project is rolled out throughout Scotland, how are we gonna handle the disappointments, when it doesn't go the way women think it's gonna go? Because ultimately, is this project about catching rapists, or about helping women who have been raped to get over what's happened, you know? Because they're two different questions, and I think... the police are treating it as it's about catching rapists, and I think Support to Report are treating it about helping women get over what's happened to them.

These implicit tensions between support and information provision, and investigative and evidential imperatives, underscore the different ways in which the nature and purposes of advocacy are conceptualised by advocacy workers and police, and impact upon the victim experience.

\section{Practical and emotional support in coping with the criminal justice process}

Victims of rape need to deal with a range of emotional and practical issues in addition to criminal proceedings. While the provision of information about the criminal justice process was deemed important, victims emphasised the value of support that addressed feelings accompanying the rape itself and the emotions associated with the journey through the criminal justice system. Due to being located within a Rape Crisis Centre, sensitivity to, and awareness of, the specific issues that affect rape victims was integrated into the provision of advocacy. From the perspective of victims, support and advice about how to cope with the 
process rather than simply information about the process was considered to be a unique feature of advocacy support that extended beyond the role of other agencies; victims frequently referred to the fact that the police were 'just doing their job' and as such, did not expect the police role to entail emotional support.

VS09: I was completely blind in what was happening. So, the police like explained, I found that they were quite harsh like they would explain to me in black and white terms what's going to happen but they don't necessarily understand what you've been through at an emotional level. Obviously, that's their job and I don't blame them for it but it can be daunting as well.

Advocacy workers were described as non-judgmental and as playing an important role in validating victims' experiences. This was of particular value in challenging circumstances where the incident reported may not meet the legal definition of rape, where there is insufficient supporting evidence, or where police questioning resulted in the victim feeling that they had not been believed. Victims also described the role that advocacy workers played in challenging conventional myths surrounding sexual violence, particularly where they impacted upon the appropriation of responsibility and blame for the incident(s) being reported.

VS07: She [Advocacy Worker] was just listening to how I was feeling. She was very supportive actually, because... I invited those guys back to my house...and she was, like, 'it doesn't matter if you walked about naked in your house. If you say no, you say no.'... I just needed somebody to say those kinds of words to me. I've always felt guilty, because I invited them back to my house... I just needed somebody to clear these wee bits in my head that I keep going through. And I was, like, no. I said no, and it should have meant no. 
VS06: But it's great to have [Advocacy Worker] there because just, it's weird because you think rape's just a physical thing, but it's more emotional... And it's good to have [Advocacy Worker] there because she totally understands it and to say to you, 'do you know, this is why you did this, do you know, it's about power'... just to help you understand like, god, he had planned it... I mean, the police were great and they're like that, 'we know a 100 per cent he did this, sometimes we're not sure, but we know he did' and that was great, but it was great to have [Advocacy Worker] there just for more the psychological things, do you know, if they were saying 'maybe he's nuts', and she's like that, 'he's not nuts'.

Highlighting perpetrator responsibility and challenging self-blame on the part of victims reflects the ethos of independent organisations such as Rape Crisis. However, the police response was still deemed crucial to how victims were able to process and recover from their experiences.

VS03: I was really, really upset. And it just felt like, all she [policewoman] needed to do was say, 'unfortunately the way the law is, at this stage, I appreciate that what happened to you has left you with the damage of a rape, but in the legal definition of the law, we can't prosecute with that'. If she'd just said it like that, it could have taken everything out of it, but what she really did, she flipping sent me back, she sent me back weeks.

It was apparent that support provided by advocacy support workers had assisted victims in being able to cope with both the criminal justice process and the reactions of others in their family and social circle, particularly when they had been met with unsupportive responses. While most had disclosed their experience to friends or family, responses to these disclosures were very mixed. While some were very supportive (and proactive in encouraging a report to be made to the police) others were less so. Even in the cases where friends and relatives were described as supportive, the additional support provided by the advocacy service during statement taking was beneficial since it meant that friends or 
relatives did not have to hear intimate or distressing details. Further, in some cases it would not have been possible for a friend or relative to be present during the police statement due to their status as a potential witness in the case.

The main benefits as described by victims were: provision of support and advice about how to cope with the criminal justice process rather than just information about it; reassurance provided by someone who understands but is independent of the process; assistance in understanding their reactions to the process (and the incident itself); having support when unable to disclose to, or rely upon, friends and family; having someone to liaise with the police and Procurator Fiscal; and having a consistent point of contact throughout the criminal justice process. It was apparent that the expansion of the pilot services' remit beyond reporting to the police was considered invaluable by interviewees, and there is a strong case for support that extends beyond conclusion of contact with the criminal justice system.

The broader context within which advocacy is delivered is key. As members of an independent women's organisation, advocacy workers have a clear ethos and work to empower victims to regain control and take decisions in their own interest, which they will then support. They are not working to increase successful prosecutions, although this may be a consequence of their involvement. Interviewees welcomed worker's independent status, not least because of the perceived formality and limitations of the role undertaken by criminal justice agencies. This was particularly the case in relation to reporting rape to the police even where the police had, as far as they were able within the context of their role, provided a supportive response. 


\section{Discussion and conclusions}

These findings make an important contribution to understanding the nature, meaning and value of advocacy work from the perspective of victims who have accessed advocacy services when reporting rape to the police. As such, this work builds upon existing knowledge gleaned in relation to domestic abuse (Howarth et al., 2009; Parmar et al., 2005; Sullivan, 1991; Taylor-Dunn, 2016) and addresses the relative lack of research evidence specific to rape advocacy, particularly from the perspective of victims (Robinson and Hudson, 2011). This is significant in view of the distinctive nature of rape and the well documented challenges associated with its reporting and prosecution (Brindley and Burman, 2012; Daly and Bouhours, 2010; Kelly et al., 2005).

Findings indicate the undisputed value of advocacy support when reporting rape to the police. Not only did advocacy support improve victims' experience of the criminal justice process and assist sustained engagement in this process, in some cases it also facilitated making a report of rape to the police in the first instance. This is in keeping with research from other jurisdictions confirming that rape survivors' experiences with medical and legal systems are improved if additional support is provided by victim advocates (see Campbell, 2006; Rich, 2014; Robinson and Hudson, 2011). While the emotional recovery of victims and the conventional aims of the criminal justice system may appear, at first sight, to be diametrically opposed (Herman, 2001), this finding also concurs with evidence that supporting victims of sexual violence throughout the criminal justice process reduces the likelihood of withdrawal from the process and therefore increases conviction rates (Lovett et al.; 2004; Robinson, 2009). However, it is necessary to understand not just if, but why, advocacy support is of benefit to victims and their engagement with the criminal justice system. 
In this study, key features included the independence of the advocacy worker from both the investigation and prosecution process, and continuity of support throughout the process. Independence forms an important context and value-base for the work. Relatedly, the dedicated nature of the advocacy worker's role in tending to the needs of the victim was of central importance. This is in line with conclusions from other research in relation to the dedicated role adopted by ISVAs in England and Wales, whereby they are able to prioritise the welfare of victims and coordinate services to meet their needs (Robinson and Hudson, 2011; Taylor-Dunn, 2016).

The advocacy worker was described by victims as providing a counter-balance to the formal, sometimes intimidating, role of criminal justice agencies. Of particular value, was the ability to understand the emotions that accompany rape and the reporting process. It is important to note that this understanding should not be confused with the provision of a 'sympathetic' response; reflecting the ethos of Rape Crisis, it was an understanding grounded in a feminist appreciation of the dynamics of sexual violence as rooted in gendered inequalities and the exercise of power and control (Nichols, 2013). Thus, Rape Crisis trained advocacy workers with an appreciation of the potentially revictimising and disempowering nature of interactions with the criminal justice system, were able to tend to the emotional and other needs of victims in a way that is different and additional to responses that criminal justice agencies are able to provide.

Nonetheless, echoing the call made by McMillan (2014) and Stern (2010), these findings also highlight the continuing need for a positive police response to reports of rape. While victims acknowledged competing police priorities within the investigation process and did not expect police officers to provide emotional support, it was apparent that the police response to their disclosure impacted significantly on their sense of justice and the validation of their experience. Similarly, Elliott et al. (2014) contend that the processes associated with 
reporting crimes to the police may be essential for the victims' recovery from their experiences; specifically, that police validation of a victim's experiences can have a vital impact upon their sense of closure, empowerment and safety. Thus, the use of advocacy workers should not mitigate police responsibility to provide an appropriate and sensitive response to disclosures of rape. As argued by McMillan (2014) in the UK and Corrigan (2013) in the US, the provision of independent victim advocacy should complement rather than replace specialist police responses if an effective response is to be made to victims of rape. In a similar vein, given that much of the secondary victimisation reported by rape victims occurs within the context of the trial (Burman, 2009), there is also an ongoing need to develop sensitive and specialist responses at the later stages of the criminal justice process. In addition to training for key criminal justice personnel, it has been argued that the provision of independent legal representation during trial is an effective way to meet the needs of the victim in the courtroom (Raitt, 2010).

Our findings indicate that advocacy support is of clear value to those reporting rape although they also raise broader questions about the outcomes sought by victims of rape. While prosecution and conviction may represent a positive criminal justice outcome and go some way to redressing the harms associated with rape, these findings highlight the importance of victims' experience of the criminal justice process and the agencies they encounter on this journey. Hence, the consistent finding that while the criminal justice process is important, belief, recognition, support, validation, voice and control remain key to recovery from rape and other forms of sexual violence (Herman, 2005; Jones and Cook, 2008; McGlynn et al., 2016; Stern, 2010). Arguably, these issues are of crucial importance to those reporting rape and other sexual offences; crimes described by McMillan (2014: 5) as those 'that fundamentally challenge a victim's sense of dignity and autonomy'. In essence, this points to the importance of procedural justice and fairness of process. This broader sense of justice can be particularly difficult to achieve within conventional criminal justice responses to 
sexual violence given the process of marginalisation described by victims in their peripheral role as witness or sources of evidence within proceedings (Herman, 2005; McGlynn et al., 2016). Moreover, findings indicate that a sense of fairness of process is especially important when cases do not proceed 'successfully' in legal terms. While such support was not included within the initial remit of S2R, this highlights the merits of independent advocacy provided by Rape Crisis and other voluntary sector organisations whereby the support provided is not contingent upon a report being made to the police, nor the stage a case may reach within the criminal justice process.

Further, current shortcomings in the criminal justice response to rape point to the ongoing need for forms of advocacy that move beyond that provided at an individual case level, to challenge social and cultural structures that exacerbate the trauma of rape. This concurs with the call by McGlynn et al. (2016) to understand victims' conceptualisations of justice as 'kaleidoscopic'; that is, as incorporating a wide ranging, on-going and continually shifting sense of justice that includes social and cultural change, thus moving beyond conventional criminal justice outcomes as embodying justice. This is a pertinent issue given that despite substantial law reform and encouraging developments in support for victims of rape, scepticism remains about the extent to which law reform alone can improve the experiences of victims (Burman, 2009; Daly, 2011; Westmarland et al., 2012), or the effectiveness of the criminal justice response to rape when it is situated within persistent discriminatory 'cultural mythologies' about women (Stubbs, 2003). Indeed, regardless of international efforts to improve the treatment of rape victims, the discretion exercised by human agents with 'attitudinal biases' are often able to subvert these efforts (Rich, 2014; Walby et al., 2015).

In conclusion, the provision of independent advocacy support is fundamental to ameliorating any 'secondary victimisation' which may arise as a result of the investigative and prosecution 
process (Kelly et al., 2005; Burman, 2009). Going forward in the context of austerity and evidence of cuts to advocacy services (Towers and Walby, 2012), lack of investment in advocacy is a false economy. The benefits of advocacy extend well beyond the emotional recovery of victims; advocacy also assists engagement in the criminal justice process. However, the provision of this form of support should not substitute or diminish the need for legal reform or for agencies involved in this process to continually review and develop their practices to prevent secondary victimisation occurring in the first instance. Hence the continuing importance of specialist independent services, such as Rape Crisis, in both service provision and influencing social, legal and cultural change (Martin, 2005; Patterson, 2009). In essence, the boundaries drawn between advocacy at an individual and societal level represents a false dichotomy; both forms of advocacy are inter-related and fundamental to improving responses to rape and the experiences of victims within the criminal justice system.

\section{Acknowledgements}

We would like to acknowledge and thank those women who participated in interviews.

\section{Funding}

This study was funded by a grant from Police Scotland and Rape Crisis Scotland for an evaluation of the Support to Report Pilot Rape Advocacy Service. 


\section{References}

Blank K, Lesur M and Logar R (2014) Women Against Violence Europe Report 2014: Specialized Women's Support Services and New Tools for Combating Gender-Based Violence in Europe. Vienna, Austria: WAVE Network.

Brindley S and Burman M (2012) Meeting the challenge? Responding to rape in Scotland. In: N Westmarland and G Ganjoli (eds.) International Approaches to Rape. Policy Press: Bristol.

Brooks O, Burman M and Kyle D (2015) Evaluation of Support to Report Pilot Advocacy Service: Summary Report. SCCJR Briefing Paper No.1/2015.

Brown B, Burman M and Jamieson L (1993) Sex Crimes on Trial: Sexual Evidence in the Scottish Courts. Edinburgh: Edinburgh University Press.

Burman M (2009) Evidencing Sexual Assault: Women in the Witness Box. Probation Journal 56(4): 379-398.

Burman M. and Johnstone J (2015) High hopes? The gender equality duty and its impact on responses to gender-based violence. Policy and Politics. 43(1): 45-60.

Brown J (2011) We mind and we care but have things changed? Assessment of progress in reporting, investigating and prosecution of rape. Journal of Sexual Aggression 17(3): 263-272.

Campbell R and Raja S (1999) The secondary victimization of rape victims: Insights from mental health professionals who treat survivors of violence. Violence and Victims 14: 261-275.

Campbell R (2006) Rape Survivors' Experiences with the Legal and Medical Systems: Do Rape Victim Advocates Make a Difference? Violence Against Women 12(1): 30-45.

Corrigan R (2013) Up against a wall: rape reform and the failure of success. New York: New York University Press.

Coy M and Kelly L (2010) Islands in the Stream: an evaluation of four London independent domestic abuse advocacy schemes. London: London Metropolitan University

Daly K (2011) Conventional and innovative justice responses to sexual violence. ACSSA Issues No. 12. Australian Centre for the study of sexual assault, Australian Government: Australian Institute of Family Studies.

Daly K and Bouhours B (2010) Rape and attrition in the legal process: A comparative analysis of five countries. Crime and Justice 39: 565-650.

Elliott I, Thomas S and Ogloff J (2014) Procedural justice in victim-police interactions and victims' recovery from victimisation experiences. Policing and Society 24(5): 588-601.

Estrich S (1987) Real Rape. Cambridge, MA: Harvard University Press.

Gregory J and Lees S (1999) Policing Sexual Assault. London: Routledge.

Herman J (2005) Justice from the Victim's Perspective. Violence Against Women, 11(5): 571574.

Hohl K and Stanko E (2015) Complaints of rape and the criminal justice system: Fresh evidence on the attrition problem in England and Wales. European Journal of Criminology 12(3): 324-341.

Home Office (2007) Cross-government Action Plan on Sexual Violence and Abuse. London: Home Office.

Home Office (2008) Saving Lives, Reducing Harm, Protecting the Public: Action Plan for Tackling Violence, 2008-11. London: Home Office.

Home Office (2009) A Resource for Developing Sexual Assault Referral Centres. London: Department of Health.

Home Office (2011) Call to End Violence Against Women and Girls. London: HM Government.

Howarth E, Stimpson L, Barran D and Robinson AL (2009) Safety in Numbers: A Multisite Evaluation of Independent Domestic Violence Advisor Services. London: Henry Smith Charity. 
Jones H and Cook K (2008) Rape crisis: responding to sexual violence. Dorset: Russell House Publishing.

Jordan J (2001) Worlds apart? Women, rape and the police reporting process. British Journal of Criminology 41(4): 679-706.

Jordan J (2011) Here we go round the review-go-round: Rape investigation and prosecutionare things getting worse not better? Journal of Sexual Aggression 17(3): 234-249.

Kelly L and Humphreys C (2000) Outreach and Advocacy Approaches in Reducing Domestic Violence: What Works? Policing and Reducing Crime Briefing Note. London: Home Office.

Kelly L, Lovett J and Regan L (2005) A Gap or Chasm? Attrition in Reported Rape Cases. London: Home Office Research Study 293.

Lovett J, Regan L and Kelly L (2004) Sexual Assault Referral Centres: Developing good practice and maximising potentials (Home Office Research Study 285). London: Research, Development and Statistics Directorate, Home Office.

Lovett J and Kelly L (2009) Different Systems, Similar Outcomes? Tracking Attrition in ReportedRape Cases across Europe. Final Research Report. London: Child and Women Abuse Studies Unit London Metropolitan University.

Maier SL (2008) 'I have heard horrible stories ...': rape victim advocates' perceptions of the revictimization of rape victims by the police and medical system. Violence Against Women 14(7): 786-808.

Martin PY (2005) Rape Work: Victims, Gender, and Emotions in Organization and Community Context. New York: Routledge.

McGlynn C, Downes I and Westmarland N (2016) Seeking Justice for Survivors of Sexual Violence: recognition, voice and consequences. In E Zinsstag and M Keenan (eds) Sexual Violence and Restorative Justice: legal, social and therapeutic dimensions. Routledge (in press).

McMillan L (2014) The role of the specially trained officer in rape and sexual offence cases. Policing and Society: An International Journal of Research and Policy. Epub ahead of print 06 May 2015. DOI: 10.1080/10439463.2014.912648.

McMillan L and Thomas M (2009) Police interviews of rape victims: tensions and contradictions. In: M Horvath and J Brown (eds). Rape: Challenging Contemporary Thinking. Cullompton: Willan Publishing, pp.255-280.

Nichols A (2013) Meaning-Making and Domestic Violence Victim Advocacy: An Examination of Feminist Identities, Ideologies, and Practices. Feminist Criminology 8(3): 177-201.

Nichols A (2014) Feminist advocacy: gendered organisations in community-based responses to domestic violence. Plymouth: Lexington.

Parkinson D (2010). Supporting victims through the legal process: The role of sexual assault service providers (ACSSA Wrap 8). Melbourne: Australian Institute of Family Studies.

Parmar A, Sampson A and Diamond A (2005) Tackling Domestic Violence: Providing Advocacy and Support to Survivors of Domestic Violence. London: Home Office Development and Practice Report 3.

Patterson D (2009) The effectiveness of sexual assault services in multi-service agencies. Harrisburg, PA: VAWnet: The National Online Resource Center on Violence Against Women.

Raitt F E (2010) Independent legal representation for complainants in rape trials., In C McGlynn and V E Munro (eds) Rethinking Rape Law: International and Comparative Perspectives. London: Routledge, pp.267-280.

Rich K (2014) Interviewing Rape Victims: Policy and Practice Issues in an International Context. Basingstoke: Palgrave Pivot.

Ritchie J, Spencer L and O'Connor W (2003) Carrying out Qualitative Analysis. In: J Ritchie and J Lewis (eds) Qualitative Research Practice: A Guide for Social Science Students and Researchers. London: Sage, pp.220-262. 
Robinson A and Hudson K (2011) Different yet complementary: Two approaches to supporting victims of sexual violence in the UK. Criminology and Criminal Justice 11(5): 515-533.

Robinson AL (2009) Independent Sexual Violence Advisors: A Process Evaluation. London: Home Office Research Report 20.

Robinson AL Hudson K and Bookman, F (2008) 'Multi-agency work on sexual violence: Challenges and prospects identified from the implementation of a Sexual Assault Referral Centre (SARC)'. Howard Journal of Criminal Justice 47(4): 411-428.

Sadan M, Dikweni L and Cassiem S (2001) Pilot assessment: The sexual offences court in Wynberg and Cape Town and related services. Pretoria, Institute for Democracy in Africa [online] http://www.afrimap.org/english/images/documents/file434e4ac9d1f29.pdf

Skinner T and Taylor H (2009) 'Being shut out in the dark' Young survivors' experiences of reporting rape and sexual assault., Feminist Criminology, 4(2): 130-150.

Stern V (2010) The Stern review: a report by Baroness Stern CBE of an independent review into how rape complaints are handled by public authorities in England and Wales. London: Home Office.

Stroh M (2000) Qualitative Interviewing. In D Burton (ed) Research Training for Social Scientists. London: Sage Publications, pp.196-214.

Stubbs J (2003). Sexual assault, criminal justice, and law and order. Women Against Violence 14: $14-26$.

Sullivan CM (1991) The provision of advocacy services to women leaving abusive partners: An exploratory study. Journal of Interpersonal Violence 6(1): 45-54.

Taylor-Dunn H (2016) The impact of victim advocacy on the prosecution of domestic violence offences: Lessons from a Realistic Evaluation. Criminology \& Criminal Justice. 16(1): 21-39.

Towers J and Walby S (2012) Measuring the impact of cuts in public expenditure on the provision of services to prevent violence against women and girls. Newcastle upon Tyne and London: Northern Rock Foundation and Trust for London

Westmarland N, Aznarez M, Brown J and Kirkham L (2012) The benefits of specialist rape teams. A report commissioned and funded by the Association of Chief Police Officers. Durham: Durham University.

Westmarland N and Ganjoli G (2012) (eds.) International Approaches to Rape. Policy Press: Bristol.

\section{WORD COUNT: 7,980}




\section{Author biographies}

Oona Brooks is a Lecturer in Criminology at the Scottish Centre for Crime and Justice Research, and a Co-ordinator of the Gender Based Violence Research Network. Oona's main research interests include rape and sexual assault, domestic abuse, legal responses to sexual offences, the prevention of sexual violence, gender and alcohol.

Michele Burman is Professor of Criminology at the University of Glasgow and a founding coDirector of the Scottish Centre for Crime and Justice Research (SCCJR). She has longstanding research interests in gender, crime and justice, with a particular interest in criminal justice responses to gender-based violence.

\section{Author contact details}

\section{Dr Oona Brooks}

Oona.Brooks@glasgow.ac.uk

Tel: +44 (0)1413307722

\section{Professor Michele Burman}

Michele.Burman@glasgow.ac.uk

Tel: +44(0)1413308618 